\title{
Un modelo etnográfico para interpretar el estilo técnico cerámico del Intermedio tardío (ap. 1100-1450 d. C.) en el altiplano de Carangas, Bolivia
}

Un modèle ethnographique pour interpréter le style technique de la céramique de l'Intermédiaire récent (1100-1450 apr. J.-C.) de l'altiplano de Carangas (Bolivie)

An ethnographic model for interpreting the Late intermediate Period (ca. 1100-1450 A. D.) technical style of pottery in the Carangas altiplano, Bolivia Juan Villanueva Criales

\section{(2) OpenEdition}

\section{Edición electrónica}

URL: https://journals.openedition.org/bifea/11958

DOI: $10.4000 /$ bifea.11958

ISSN: 2076-5827

\section{Editor}

Institut Français d'Études Andines

\section{Edición impresa}

Fecha de publicación: 1 abril 2020

Paginación: 171-193

ISSN: 0303-7495

\section{Referencia electrónica}

Juan Villanueva Criales, «Un modelo etnográfico para interpretar el estilo técnico cerámico del Intermedio tardío (ap. 1100-1450 d. C.) en el altiplano de Carangas, Bolivia», Bulletin de l'Institut français d'études andines [En línea], 49 (1) | 2020, Publicado el 08 agosto 2020, consultado el 25 agosto 2021. URL: http://journals.openedition.org/bifea/11958 ; DOl: https://doi.org/10.4000/bifea.11958

\section{(c) (i) $\ominus$}

Les contenus du Bulletin de l'Institut français d'études andines sont mis à disposition selon les termes de la licence Creative Commons Attribution - Pas d'Utilisation Commerciale - Pas de Modification 4.0 International. 


\title{
Un modelo etnográfico para interpretar el estilo técnico cerámico del Intermedio tardío (ap. 1100-1450 d. C.) en el altiplano de Carangas, Bolivia
}

\author{
Juan Villanueva Criales*
}

\begin{abstract}
Resumen
Este texto discute la noción de la cerámica como símbolo de identidad étnica, clave en el modelo interpretativo de «señoríos aymaras», que es el más aceptado por la arqueología precolonial para el período Intermedio tardío (1100 - 1450 d. C.) en el altiplano boliviano. Proponemos una interpretación alternativa con base en una «arqueología de los encuentros»; que resalta el rol de la cerámica en la construcción de comunidades imaginadas mediante prácticas comensalistas, y el enfoque de estilo técnico, basado en la etnografía sobre alfarería andina. Los resultados de análisis petrográficos de cerámica de cuatro regiones del altiplano de Carangas (Oruro - Bolivia) en comparación con patrones morfológicos y decorativos, son discutidos en relación con el modelo etnográfico de los «alfareros golondrinos». Este modelo permite repensar a los agentes involucrados en la producción y distribución cerámica en el Intermedio tardío, y reflexionar sobre la relación entre cerámica, comunidad e identidad.
\end{abstract}

Palabras clave: cerámica arqueológica, petrografía, período Intermedio tardío, Bolivia, Andes surcentrales, estilo técnico

Jefe de unidad de Investigación. Museo Nacional de Etnografía y Folklore, La Paz, Bolivia. E-mail: juan.villanuevacriales@gmail.com 


\title{
Un modèle ethnographique pour interpréter le style technique de la céramique de I'Intermédiaire récent (1100-1450 apr. J.-C.) de I'altiplano de Carangas (Bolivie)
}

\author{
Résumé
}

Ce texte s'intéresse à la notion de céramique en tant qu'emblème de l'identité ethnique, clé dans le modèle d'interprétation des señoríos aymaras, qui est la plus acceptée par l'archéologie précoloniale pour la période de l'Intermédiaire récent (1100-1450 après J.-C.) dans les hautes terres boliviennes. Nous proposons une lecture alternative sur une « archéologie des rencontres », en soulignant le rôle de la céramique dans la construction de communautés imaginées à travers des pratiques commensales, et I'approche du style technique, sur l'ethnographie de la poterie andine. Les résultats des analyses pétrographiques céramiques de quatre régions du plateau de Carangas (Oruro - Bolivie), comparés à des ensembles morphologiques et décoratifs, sont examinés à la lumière du modèle ethnographique des potiers itinérants. Ce modèle nous permet de repenser les agents impliqués dans la production et la distribution de la céramique à la fin de l'Intermédiaire récent, et de réfléchir sur la relation entre céramique, communauté et identité.

Mots-clés : céramique archéologique, pétrographie, période Intermédiaire tardive, Bolivie, Andes du centre-sud, style technique

\section{An ethnographic model for interpreting the Late intermediate Period (ca. 1100-1450 A. D.) technical style of pottery in the Carangas altiplano, Bolivia}

\begin{abstract}
This text discusses the notion of pottery as a symbol for ethnic identity. This is crucial for the interpretative model of Señoríos Aymaras, which is widely accepted by pre-colonial archeology for the Late Intermediate Period (1100-1450 AD) in the Bolivian highlands. We propose an alternative interpretation based on an "archeology of encounters". This highlights the role of ceramics in the construction of imagined communities through commensal practices. A technical style approach is utilized based on the ethnography of Andean pottery. The results of the petrographic analysis of ceramics from four regions on the Carangas plateau (Oruro - Bolivia) was compared with an analysis of morphologic and decorative patterns, and these are then discussed in relation to the ethnographic model of "swallow potters". This model makes it possible to rethink the agents involved in Late Intermediate Period pottery production and its distribution, and to reflect on the relation between pottery, community and identity.
\end{abstract}

Keywords: archaeological ceramics, petrography, Late Intermediate Period, south-central Bolivian Andes, stylistic technique

El estilo cerámico ha sido una pieza fundamental para construir la narrativa de «señoríos aymaras» que da cuenta del período intermedio tardío (1100-1450 d. C.) en las tierras altas bolivianas. Este texto discute la pertinencia del estilo cerámico —en ocasiones reducido solo a variables morfológicas «no funcionales» y decorativas, lo que en este texto denominamos estilo externo- como indicador de identidad étnica y fronteras sociales. Argumentamos que la cerámica puede ser entendida como un elemento de confluencia y encuentro en la construcción 
de comunidades imaginadas. Este concepto de Anderson (1983), aplicado a la Arqueología, refiere a grupos humanos cuyos lazos comunitarios se reproducen mediante dinámicas ajenas a la coresidencia (Isbell, 2000: 250). Esto implica repensar el rol de los alfareros y sus mecanismos de producción e intercambio, así como cambiar el enfoque analítico de la cerámica hacia las cadenas operatorias y los estilos técnicos o tecnológicos basados en la idea de que las conductas y técnicas son guiadas por elecciones humanas, cuya arbitrariedad genera variabilidad en los patrones de cultura material (Stark, 1998: 6). Este cambio de enfoque tiene implicancias para la arqueología de Carangas y del Intermedio tardío en general.

Comenzamos con un recuento de antecedentes y una crítica a la aplicación del concepto de señorío al panorama preincaico del altiplano boliviano, con base en sus orientaciones políticas subyacentes, problemas metodológicos e inadecuaciones respecto de los datos arqueológicos. Luego, delineamos un enfoque de arqueología de los encuentros, basado en la construcción de comunidades imaginadas mediante el comensalismo. El comensalismo involucra eventos de consumo comunitario de alimentos que difieren de las prácticas cotidianas (Dietler, 1996: 89), donde la cerámica facilita la interacción en lugar de la separación. Posteriormente, presentamos el espacio de Carangas (Oruro, Bolivia) como fundamentalmente heterogéneo, de donde emergen los criterios para la muestra y métodos empleados. A partir del estudio petrográfico de pastas cerámicas de cuatro regiones prospectadas en el altiplano de Carangas, analizamos su relación con formas cerámicas, distribución espacial y motivos decorativos. Las relaciones detectadas nos impulsan a observar la cerámica desde el punto de vista de estilo técnico, acudiendo a la etnografía andina sobre producción e intercambio alfarero- $y$, concretamente, sobre el fenómeno de alfareros golondrinos, como fuente de inspiración para reconsiderar la agencia de los alfareros y de los consumidores en la producción cerámica precolonial.

\section{EL INTERMEDIO TARDÍO ALTIPLÁNICO Y EL ESTILO CERÁMICO}

Desde la década de 1970, el estudio arqueológico del Intermedio tardío en las tierras altas bolivianas se basa en una idea dominante, que es la presencia de un conjunto de señoríos étnico-territoriales diversos, frecuentemente enfrentados (Ponce Sanginés, 1978: 18). Esta idea se implanta en Bolivia a partir de una coincidencia entre dos factores que nombraremos brevemente, pues han sido desarrollados en otra ocasión (Villanueva, 2017).

El primer factor es la implantación de una arqueología con objetivos nacionalistas. Su narrativa central era el surgimiento del Imperio Tiwanaku (ap. 500-1100 d. C.), cuyas características urbanas, expansivas y grandes logros arquitectónicos técnicos (Ponce Sanginés, 1976), servirían como fuente de orgullo patrio para todos los bolivianos, incluidas las élites urbanas. Sin embargo, esta narrativa contiene también una forma de desligar este pasado brillante de aquellos bolivianos que debían ser asimilados culturalmente y «modernizados» por las políticas nacionalistas: los indígenas, especialmente aimaras. Las poblaciones del Intermedio tardío o 
«post-Tiwanaku» son identificadas, entonces, como los antecesores culturales de los aimaras: son «señoríos aimaras» luego incanizados e hispanizados. Son caracterizados como bárbaros, en pugna constante y sin logros culturales de relevancia (Ponce Sanginés, 1978: 18). Según esta narrativa, la decadencia cultural en que se sume el mundo indígena desde entonces justificará su rescate por élites urbanas, legitimadas por su origen Tiwanaku, pero a la vez capaces de transformar a los indígenas en componentes del Estado nación moderno.

El segundo factor es la identificación de «señoríos aimaras» mediante documentos históricos de los siglos XVI y XVII (Bouysse-Cassagne, 1987; Saignes, 1986). Estas investigaciones entregan a los arqueólogos herramientas para buscar la profundidad temporal de estas formaciones sociales, mediante la arqueología histórico-cultural. Una característica de esta es su carácter cladístico, es decir su énfasis en clasificar en categorías rígidas y cerradas, inspiradas en las clasificaciones filogenéticas de la biología evolutiva (Bernardini, 2005: 31-32). Esta práctica genera taxonomías donde las entidades culturales son percibidas como unidades internamente coherentes, delimitadas espacialmente- y persistentes en el tiempo. En el caso del altiplano boliviano, desde la década de 1980 se identifican culturas arqueológicas y se mapean sus dispersiones territoriales, arribando a un mapa arqueológico del Intermedio tardío isomorfo a los esquemas de origen etnohistórico desarrollados previamente (fig. 1). En estas definiciones, el indicador material más empleado para distinguir mutuamente a estas «culturas arqueológicas» fue la cerámica. Sin embargo, la misma se consideró casi exclusivamente en términos de aquellos aspectos morfológicos y decorativos «no funcionales», una aproximación que denominaremos «estilo externo». No se incluyeron en estas definiciones consideraciones relacionadas con los materiales, gestos y técnicas de manufactura.

Entre los problemas de la implantación del enfoque cladístico en la arqueología del Intermedio tardío citamos la cuestionable agenda política presente en su origen; el esencialismo y ahistoricidad, notorias al concebir trayectorias inmóviles de más de dos siglos de duración; el asumir conceptos de territorialidad y de frontera de corte occidental, ajenos a las dinámicas más segmentarias y fluidas propias de las sociedades andinas; y el uso del estilo externo como marcador de distinciones y fronteras sociales.

La cerámica del Intermedio tardío ha sido abundantemente identificada en el altiplano (Albarracín-Jordán, 1996; Bennett, 1934; Michel, 2000; Rydén, 1947). Tiene un repertorio morfológico limitado a ollas, cántaros, jarras y cuencos, los tres últimos usualmente engobados en rojo o naranja y pintados con negro o marrón oscuro. Especialmente en el caso de los cuencos, se identifican motivos como círculos punteados o hachurados, puntos, espirales, siluetas de camélidos, asteriscos, cruces, líneas onduladas verticales u horizontales, entre otros. Se ha tendido a identificar a algunos de estos motivos como emblemáticos de uno u otro señorío, pero estas hipótesis se basan en tendencias cuantitativas al interior de conjuntos recolectados dentro de cada «territorio étnico» y sin trabajo comparativo. Un primer estudio comparativo en el altiplano central permite ver que los motivos decorativos no varían sustancialmente entre ambos lados de la 


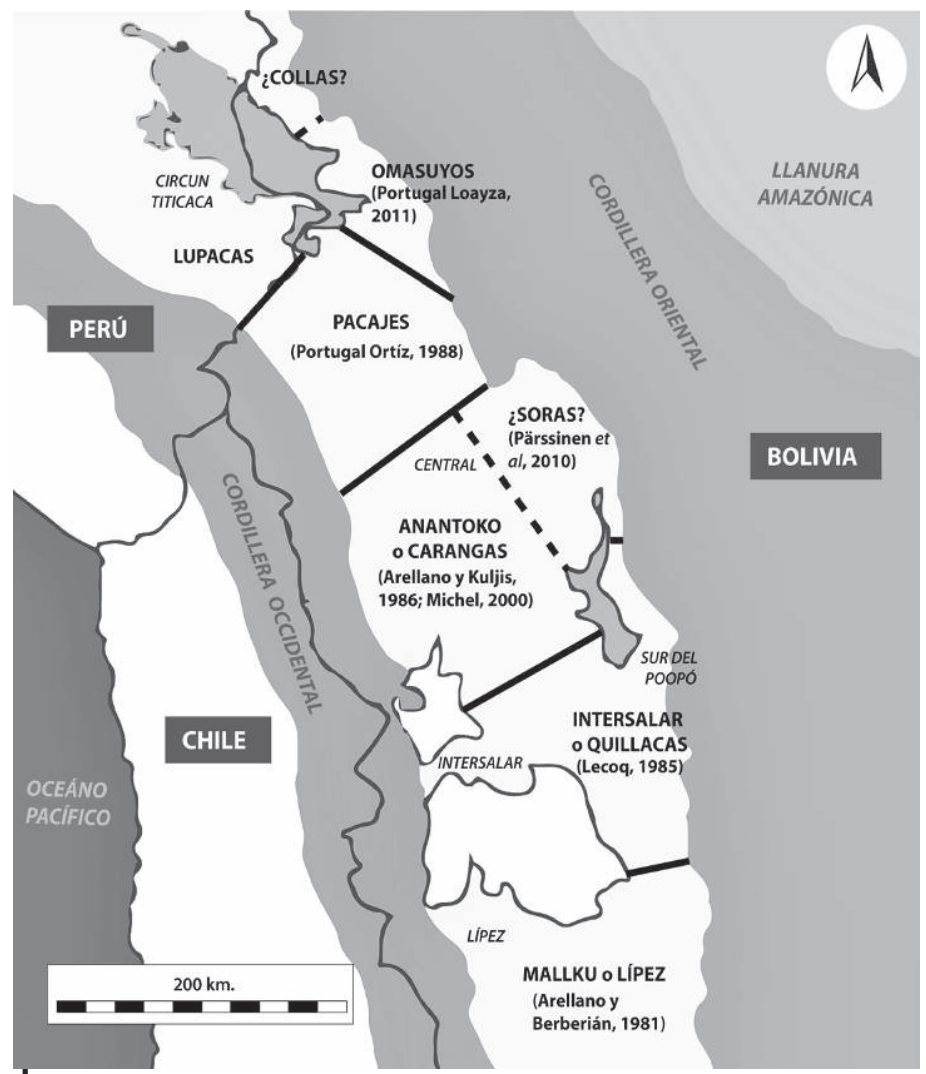

Figura 1 - Mapa de señoríos definidos arqueológicamente para el Intermedio tardío en el altiplano boliviano

(C) Juan Villanueva

«frontera» del río Mauri-Desaguadero, sugiriendo que un problema similar podría estar ocurriendo en otras «fronteras étnicas» (Villanueva, 2015: 218).

Ante los problemas políticos, teóricos y de correspondencia con el registro que plantea el esquema de señoríos altiplánicos y el uso del estilo externo como un marcador de fronteras sociales, entre 2011 y 2014, el Proyecto Arqueológico Altiplano Central (PAAC) estudió arqueológicamente el Intermedio tardío al interior del supuesto territorio étnico del señorío Carangas. Su objetivo fue evaluar indicadores de homogeneidad estilística y de centralización, criterios tradicionalmente empleados para identificar un «señorío étnico» similar a los documentados etnohistóricamente. Nuestro enfoque teórico se basó en una «arqueología de los encuentros», desde un concepto de comunidad imaginada. El mismo, inicialmente propuesto por Anderson (1983) para la consideración antropológica de cualquier comunidad mayor a una aldea, supone que los lazos entre miembros son creados e imaginados, y no se deben necesariamente al permanente contacto presencial. Isbell (2000) aplica el concepto a la Arqueología, 
distinguiéndolo de la comunidad natural, basada en la experiencia de compartir el espacio residencial.

Algunos estudiosos del área centro-sur andina, emplean referencias etnohistóricas y etnográficas para otorgar a las formaciones sociales prehispánicas un carácter segmentario (Albarracín-Jordán, 2007) y corporativo (Nielsen, 2006). Nuestra idea base es que, en un contexto semejante, territorialmente proclive a la discontinuidad y a la movilidad, las instancias periódicas de confluencia comensalista y ceremonial de segmentos sociales no co-residenciales serían importantes para construir comunidades imaginadas. En el caso del Intermedio tardío altiplánico, las torres funerarias o chullpares constituyen un rasgo notable en el paisaje (Gil García, 2010; Kesseli \& Pärssinen, 2005; Nielsen, 2008; Villanueva, 2015). En el caso de Carangas, estas torres se agrupan en sitios de índole ceremonial-funeraria (chullperíos), separadas de los asentamientos residenciales y, no obstante, cubiertos de fragmentos de cerámica de servido.

Así, los chullperíos serían locus potenciales para ceremonias que relacionaban a los seres humanos con los muertos, donde el festejo con abundante comida y bebida permite negociar lazos comunitarios entre grupos humanos que no necesariamente residen juntos. Este enfoque tuvo dos consecuencias en nuestra manera de pensar la cerámica. La primera, dejar de considerarla un elemento de separación, para verla como un material para la confluencia y el encuentro. La segunda, considerar que la cerámica encontrada en contexto de uso, tuvo que haber sido obtenida de algún segmento social productor. Esta idea implica visualizar a alfareros que entablan lazos y afiliaciones comunitarias, al tiempo que insertan su cerámica en dinámicas de intercambio y construcción de comunidades. Los trabajos etnográficos sobre grupos especializados de alfareros que intercambian su producto principalmente - aunque no exclusivamente - al interior del propio ayllu mayor (Cremonte, 1984: 256-257; Harris, 1986: 264-265), han inspirado esta noción.

Finalmente, esta idea nos llevó a atender a ciertas características de la cerámica como resultados de decisiones técnicas, que los alfareros son más o menos proclives a variar. Trabajos etnográficos enfocados en la alfarería andina y de otras regiones del mundo (Druc, 2013: 493-494; Roux, 2011: 80-82; Stark et al., 2000: 304-306), sugieren que pasos como la elección de materiales, la preparación de la pasta o la elaboración del ceramio, pueden ser menos variables para los alfareros que la decoración o «estilo externo», que variaría de modo más fluido, y tal vez, como veremos, con cierta agencia de los consumidores de cerámica.

\section{EL ENTORNO CARANGAS Y EL PAAC}

La meseta altiplánica se extiende por todo el occidente de Bolivia; se caracteriza por la bifurcación de la cordillera de los Andes en dos segmentos que encierran la meseta: la cordillera oriental la separa de los valles húmedos, yungas y llanuras amazónicas. La cordillera occidental la separa de los valles secos y de la costa del Pacífico. Tiene una altitud promedio de 4000 m s.n.m. y un clima frío, con marcadas variaciones estacionales entre tiempos secos y húmedos. El altiplano 
se divide en tres grandes segmentos de norte a sur: el altiplano norte o cuenca del Titicaca, el altiplano central y el altiplano sur o Lípez. La humedad en estos segmentos decrece en dirección norte-sur; por tanto, el altiplano central es un intermedio entre la húmeda cuenca del Titicaca, y la casi desértica región de Lípez. En este trabajo nos concentramos en una porción del altiplano central denominada altiplano de Carangas, por el señorío aimara que habitaba esta zona en tiempos coloniales tempranos (Bouysse-Cassagne, 1987; Saignes, 1986). Carangas ha sido estudiado desde la etnohistoria, (Medinacelli, 2008; 2010; Rivière, 1988), y es descrito como una entidad territorial jerárquica, con varias cabeceras o asentamientos mayores y una capital, Corquemarca/Choquecota, en el noreste del territorio. Los límites de este señorío fueron empleados por Michel (2000) en la primera síntesis arqueológica de la región, donde Carangas es delimitado por los ríos Mauri y Desaguadero al norte; la falla de Corque y el lago Poopó al este; el río Lakajahuira y el salar de Coipasa, al sur; y la cordillera occidental al oeste (fig. 2). La etnohistoria y arqueología bolivianas tienden a considerar Carangas como un paisaje altiplánico homogéneo, de donde derivan caracterizaciones económicas, sociales y culturales. Medinacelli (2010) caracteriza a los carangas históricos como poseedores de una economía y cultura fundamentalmente pastoril. Michel (2000: 84-85) extrapola esta noción de homogeneidad hacia el período inmediatamente anterior a los incas, el Intermedio tardío (1100-1450 d. C.), cuando habría existido en la región un señorío consolidado, definido por sus patrones de asentamiento doméstico, con sitios fortificados de altura o pukaras y otros no fortificados; sus patrones funerarios, entre los que destacan los sitios de chullpares; y un estilo externo de cerámica, el estilo Carangas, indicando homogeneidad y demarcando su extensión territorial.

Sin embargo, una mirada más detallada al altiplano de Carangas nos muestra que no es homogéneo climáticamente, aunque debemos notar que no existen aún estudios paleoclimáticos exhaustivos en la región, que podrían cambiar en algo nuestras interpretaciones. Las zonas orientales de Carangas tienen clima de estepa, más templado y húmedo por su cercanía con la cordillera oriental, hacia la que suben los vientos amazónicos, en tanto las zonas occidentales tienen clima de tundra (Montes de Oca, 2005). También existen diferencias latitudinales, siendo el norte más húmedo por la presencia del lago Poopó, y el sur más seco, con lagos desecados como el salar de Coipasa. En el noroeste, el deshielo de la cordillera occidental genera pastizales húmedos (bofedales), ideales para la cría intensiva de alpacas. En la franja oriental, los suelos salobres altiplánicos son reemplazados por suelos de erosión de la falla montañosa de Corque que, a la vez, abriga del viento, creando microclimas fértiles para la agricultura. Este rasgo es más agudo en el noreste, donde la falla de Corque es más alta. En tanto, el sudeste se ubica a orillas del lago Poopó, fuente de avifauna y pesca. Finalmente, el sudoeste de Carangas, constituye la zona más seca. Mientras que las otras tres zonas se afilian a la categoría ecológica de puna seca, el sudoeste es una puna desértica, con vegetación de dunas (Montes de Oca, 2005). Subsisten pajonales con arbustos o matorrales que alimentan las llamas, y la cercanía con el salar de Coipasa implica acceso privilegiado a un recurso escaso en el resto de Carangas. 


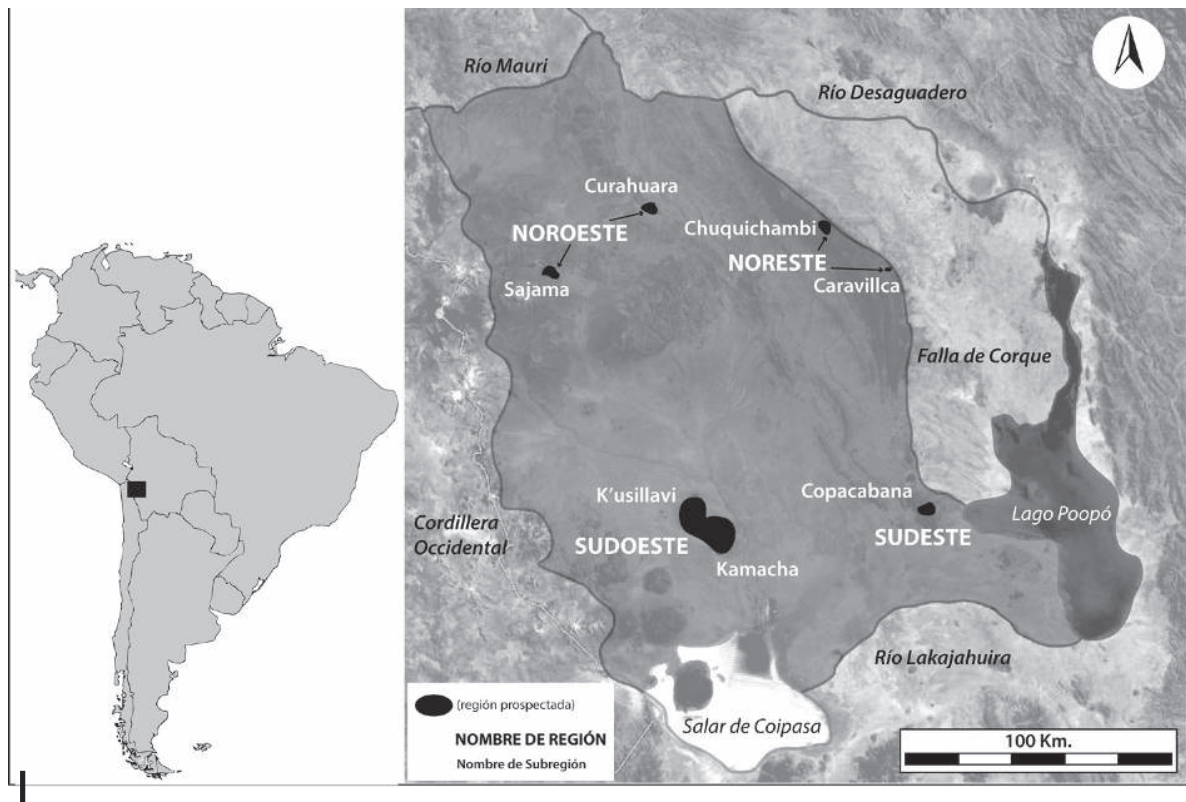

Figura 2 - Delimitación del altiplano de Carangas y de las zonas prospectadas para este estudio (C) Juan Villanueva

Estos factores determinan distintos regímenes ecológicos en el altiplano de carangas, lo que implica potenciales diferencias en la orientación económica preponderante y concentración poblacional de sus habitantes. Por ello, el planteamiento de investigación del PAAC incluyó prospecciones remotas y pedestres, en cuatro regiones de Carangas que fuesen representativas de estas diferencias. Esto permitió detectar diferencias en el patrón de asentamiento, uso de recursos y funcionamiento de los chullperíos, detalladas en anteriores publicaciones (Villanueva, 2015). El marco de arqueología de los encuentros descrito líneas arriba nos llevó a enfatizar el rol del comensalismo en los chullperíos, empleando la cerámica presente como resultado de estas prácticas para delinear intensidades y direcciones de interacción.

El PAAC recorrió cuatro regiones distribuidas sobre el altiplano de carangas, divididas en siete subregiones (fig. 2). Detectó 49 sitios del Intermedio tardío, entre 16 asentamientos y 33 chullperíos. La recolección de cerámica fue de cobertura total en los asentamientos menores a 5 ha y en los chullperíos, y por muestreo en asentamientos mayores a 5 ha, lo que permitió obtener una muestra de 2618 tiestos. El análisis cerámico duró cinco meses: tres para el análisis macroscópico de forma, decoración, engobe, cocción, tratamiento de superficie y pastas; y dos empleando microscopía petrográfica sobre secciones delgadas en el Laboratorio de Análisis e Investigaciones Arqueométricas (LAIA) en Arica, Chile, sobre una muestra de 100 fragmentos, con aumentos de 4x, 10x y 20x. El análisis petrográfico fue cualitativo y con ponderaciones semicuantitativas sobre la presencia de inclusiones en las secciones delgadas. La base de datos resultante fue 
analizada mediante IBM SPSS Statistics v.20., empleando la técnica de análisis de agrupamientos (cluster analysis) jerárquico, técnica multivariable que agrupa los casos según el orden e importancia de variables ordinales discretas.

\section{LA CERÁMICA DEL INTERMEDIO TARDÍO EN CARANGAS}

Dividimos este apartado en cuatro partes. Las dos primeras abordan la elección de materias primas y preparación de la pasta, como pasos usualmente poco variables del estilo técnico. Analizamos las inclusiones de las pastas y su distribución espacial sobre el altiplano de carangas y las características de dureza y granulometría en relación con las formas cerámicas. La tercera parte incide en la decoración que la arqueología tradicional del Intermedio tardío ha empleado como indicador de estilo externo y, por tanto, de identidad étnica, como mencionamos. Analizamos los motivos pintados y su distribución espacial. La cuarta parte relaciona pastas y motivos pintados.

\section{1. Definición de pastas por inclusiones y distribución espacial}

El análisis petrográfico y el tratamiento estadístico permitieron generar un dendrograma y distinguir seis pastas, que describimos en términos de matrices e inclusiones (fig. 3; cuadro 1). Las inclusiones corresponden a los componentes geológicos del entorno altiplánico (Mobarec \& Murillo, 1996), y las diferencias entre pastas parecen deberse a las fuentes de arcilla, a juzgar por el reducido tamaño, redondez y buen ordenamiento de las inclusiones, con una excepción que describimos en seguida.

Para describir las pastas seguiremos el orden evidenciado por el dendrograma. La pasta 6 es la primera en distinguirse claramente por la ausencia de vidrio volcánico, un atributo que podría implicar una fuente de arcilla geológicamente distinta. Aunque existen estudios geológicos de la región (Mobarec \& Murillo, 1996), no tienen suficiente definición sobre fuentes de arcilla. Sin embargo, pensamos que el vidrio volcánico podría ubicarse en las cercanías de antiguos volcanes. La franja occidental es la única de Carangas cercana a los volcanes de la cordillera occidental (fig. 4). Por tanto, planteamos como hipótesis que la fuente de arcilla de esta pasta se situaría en la franja oriental. La pasta 6 tiene además abundante biotita y feldespatos, así como cuarzo en mediana proporción.

En segundo lugar, se desprende la pasta 1. El rasgo más distintivo de esta pasta es la presencia de cantidades altas a medias de inclusiones pumíceas. En ocasiones anteriores (Villanueva, 2015), sugerimos que estas inclusiones serían microfósiles de esponjas. Sin embargo, trabajos petrográficos recientes en la cuenca del Titicaca han relacionado etnoarqueológicamente estas inclusiones con cenizas volcánicas (Roddick, 2015: 141). El uso de este material llamado p'oke como antiplástico; está documentado etnográficamente (Arnold, 2003; Sapiencia de Zapata et al., 1997), y explicaría este rasgo de la pasta 1. Las otras inclusiones de esta pasta son 


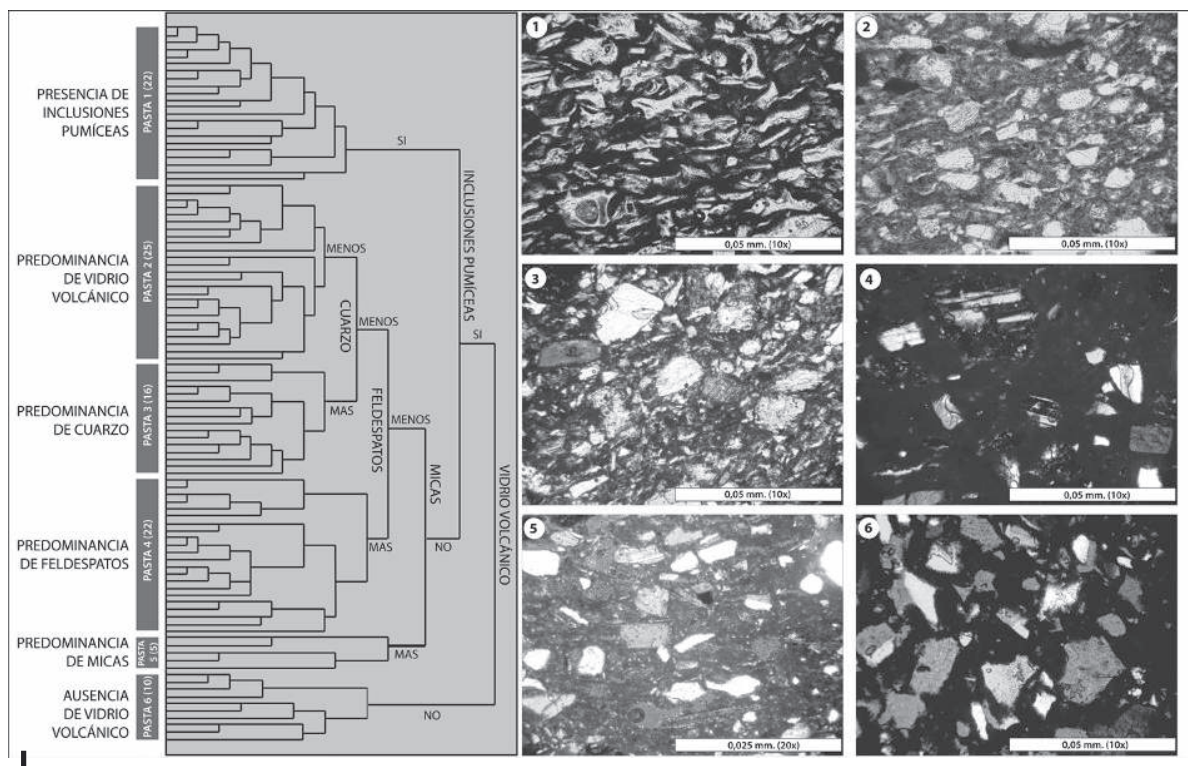

Figura 3 - Dendrograma de definición de pastas cerámicas y microfotografías de pastas definidas

(c) Juan Villanueva

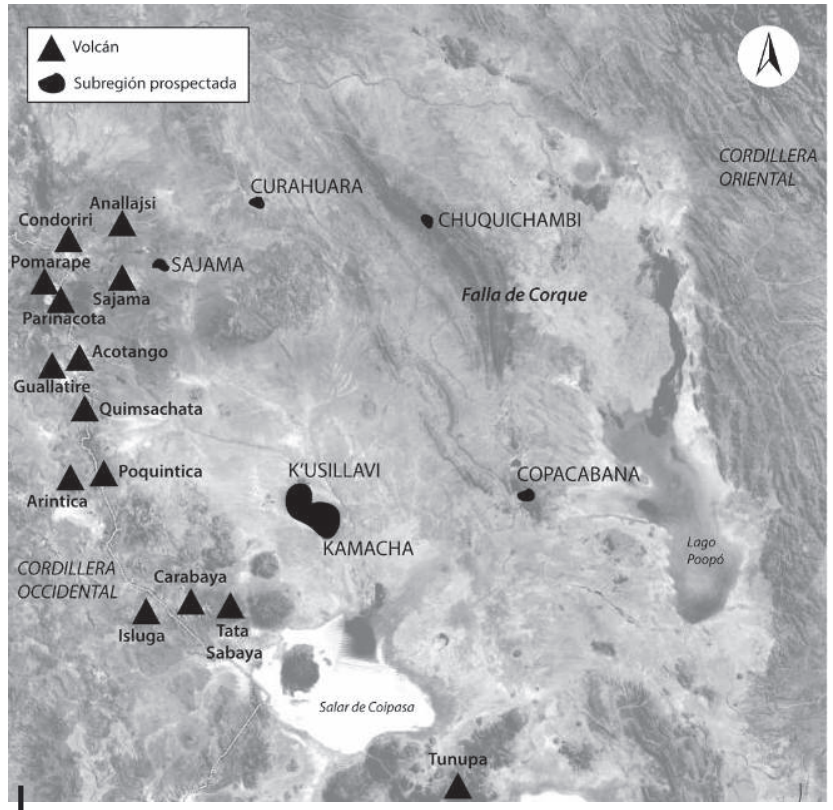

Figura 4 - Mapa del altiplano de Carangas ubicando a los volcanes en relación con las subregiones prospectadas

(c) Juan Villanueva 
Altiplano de Carangas: estilo técnico cerámico del Intermedio tardío (ap. 1100-1450 d. C.)

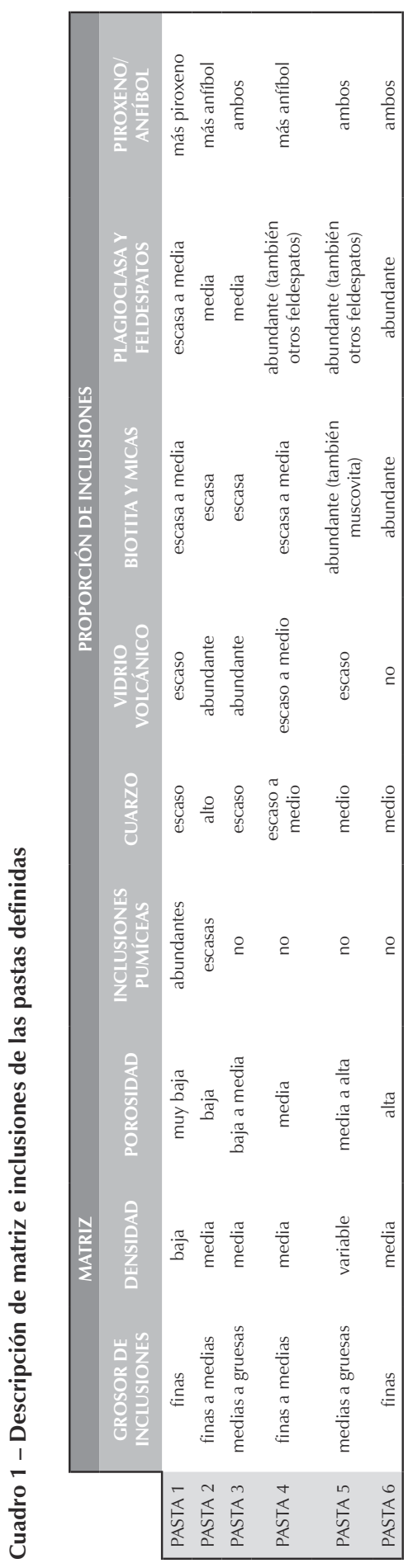


proporciones bajas de cuarzo y vidrio volcánico así como medianas de biotita y plagioclasa.

Posteriormente, el dendrograma separa las pastas 5 y 4, con base en la relativa abundancia de alguna inclusión. La pasta 5 posee mayor proporción de micas, tanto biotita como muscovita, cantidades moderadas de cuarzo y escasas de vidrio volcánico. En la pasta 4 predominan variados feldespatos (plagioclasa, sanidina, microclino), mientras que el vidrio, cuarzo y biotita son minoritarios. Las inclusiones de feldespatos y de mica son redondeadas y de tamaño homogéneo, y posiblemente se deban a la fuente de arcilla, aunque su uso como antiplástico no puede descartarse.

Finalmente, el dendrograma separa las pastas 2 y 3 . La principal diferencia entre ambas es que la pasta 2 presenta abundante cuarzo y vidrio volcánico, mientras que en la pasta 3 el vidrio es mayoritario y el cuarzo es menos abundante. Por lo demás, ambas pastas son bastante similares, y tendemos a tratarlas conjuntamente.

Acerca de las proporciones cuantitativas de las pastas en nuestra muestra, existen tres pastas mayoritarias: la 2-3 (42\%), la 1 (31\%) y la 6 (18 \%) (fig. 5). Las pastas 4 y 5 se presentan de modo muy minoritario. Al desglosar esta distribución entre las regiones estudiadas, se observa que las pastas no son exclusivas de cierta región, ni se distribuyen entre regiones homogéneamente, existiendo más bien tendencias cuantitativas. La pasta 1 circula por todas las regiones, aunque es preferida en el noroeste, donde representa más de la mitad del total, y en el sudeste. Las pastas 2 y 3 también aparecen en todas las regiones, pero de modo más reducido en el noreste. Precisamente el noreste se distingue por emplear abundante pasta 6, casi la mitad del total. Esta pasta circula minoritariamente por la franja sur de Carangas, y casi no llega al noroeste. Finalmente, las pastas 4 y 5 se concentran en el sudoeste; la pasta 5 no se encuentra fuera de dicha región, y la 4 circula minoritariamente hacia el sudeste y el noroeste.

\section{2. Dureza, granulometría y relación con formas cerámicas}

Se identificaron dos pastas duras: la pasta 1 (fina) y la pasta 2 (media). Las pastas semiduras son la pasta 3 (gruesa) y la pasta 4 (media). Las pastas porosas son la pasta 5 (gruesa) y la pasta 6 (fina). La relación entre formas y pastas (fig. 6) destaca la ausencia de «especialización» de las pastas en la manufactura de las formas, aunque existen tendencias cuantitativas. Las formas parecen vincularse un poco a la dureza de la pasta, sobre todo en relación con el tamaño del ceramio, o tal vez con algún aspecto funcional como resistencia térmica o mantenimiento de temperatura. Los cántaros y ollas, de mayor tamaño, emplean más pastas blandas como la 5 y la 6 . La pasta 5 se usa casi exclusivamente para formas grandes, mientras la 6, más fina, se usa también para jarras y cuencos. Las pastas semiduras se distribuyen de modo menos claro; ambas se usan para ollas, aunque la pasta 3, más gruesa, es más empleada para cántaros y jarras, y la pasta 4, más fina, para cuencos. Finalmente, las pastas duras se usan más para jarras y cuencos, aunque 


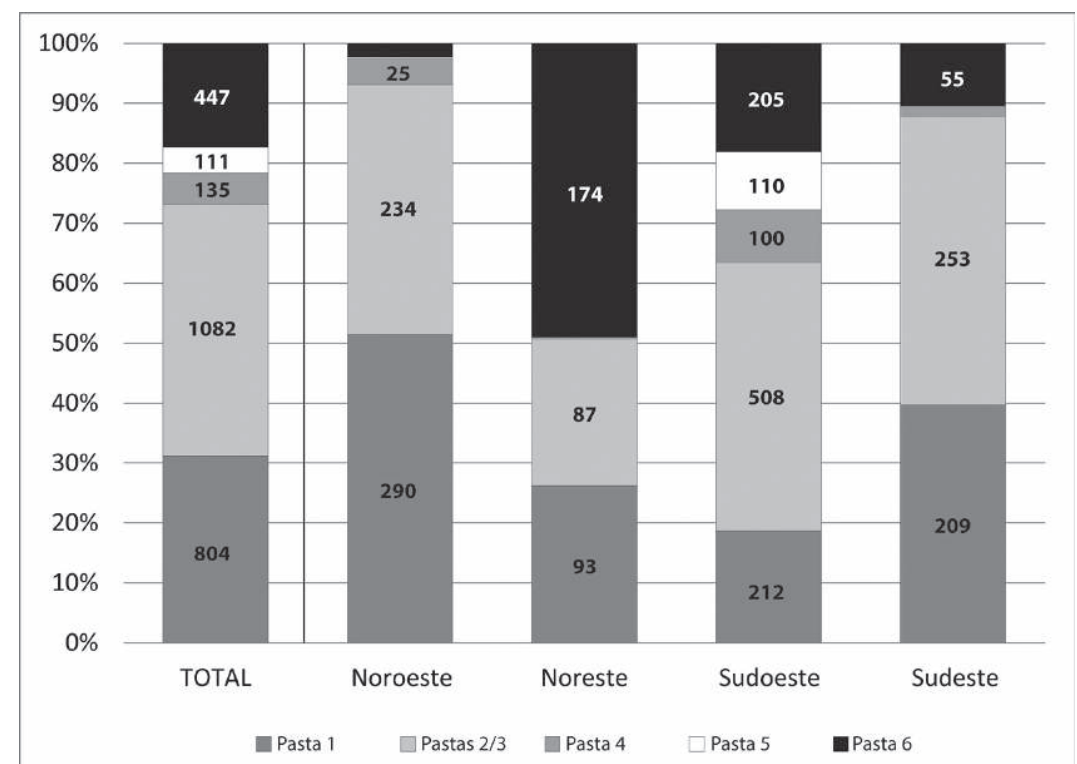

Figura 5 - Gráfico de distribución de pastas según las regiones

(C) Juan Villanueva

también para formas grandes. Una vez más, los cántaros y jarras emplean más la pasta 2, media, mientras que la versión más fina, la pasta 1, es usada más para cuencos.

\section{3. Motivos pintados y su distribución}

Analizamos los fragmentos de cuencos que presentan patrones de decoración claros en la cara interna. Aunque los cántaros y jarras llevan decoración, sus motivos se ordenan en composiciones más grandes, difíciles de estimar con base en fragmentos. Por ello, se ha trabajado sobre una muestra de 945 tiestos. La casi totalidad corresponde a formas y patrones decorativos del altiplano, con dos tiestos procedentes, posiblemente, de la precordillera de Arica (estilo Charcollo, según Muñoz \& Chacama, 2006). En la cerámica altiplánica central, es común la pintura interna (Michel, 2000; Pärssinen, 2005; Patiño \& Villanueva, 2008). La mayor parte de los motivos pintados de nuestra muestra se ubica en el interior, por lo que consideramos solo estos registros, pero debe notarse que los escasos fragmentos de cuencos decorados en ambas caras provienen de la región sudeste, cercana al sur del Poopó y al Intersalar, donde esta característica es común (Arellano \& Berberian, 1981; Lecoq, 1999). Los motivos pintados dentro de los cuencos son diversos, como señala la bibliografía sobre la cerámica Pacajes y Carangas (Michel, 2000; Pärssinen, 2005; Villanueva, 2015). Con fines de análisis, creamos algunas categorías lo más abarcadoras posibles (fig. 7). 


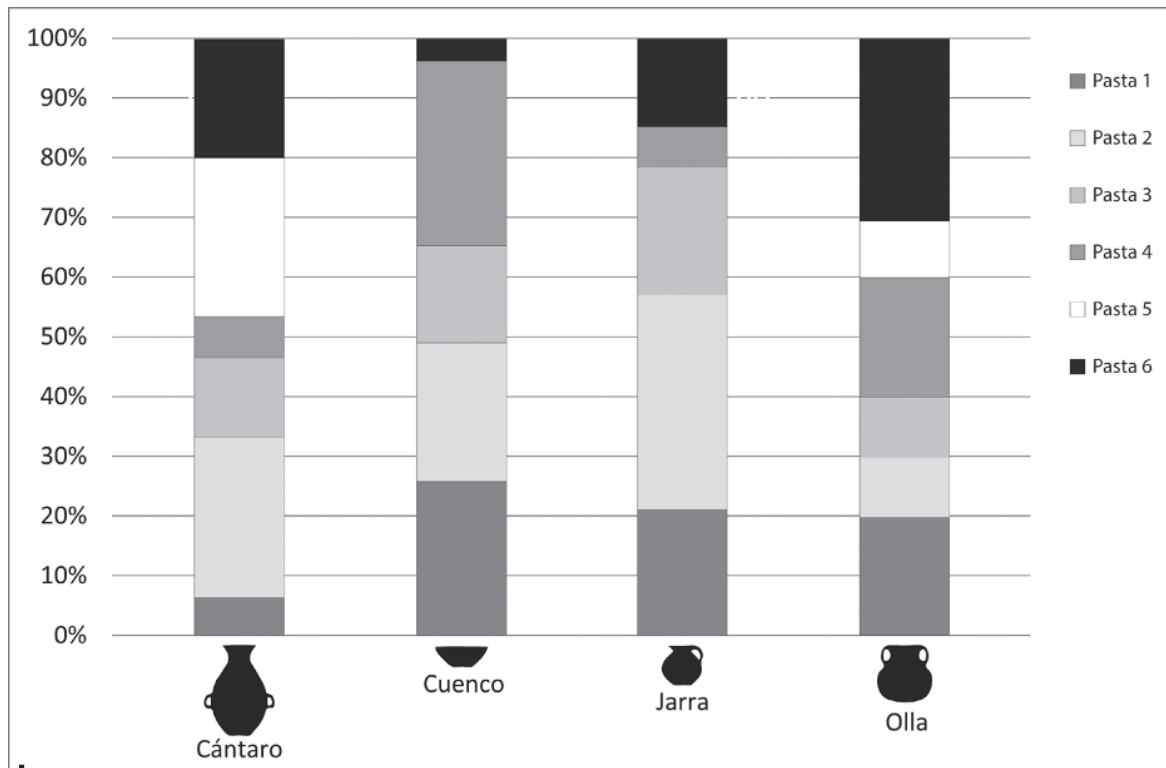

Figura 6 - Gráfico de relación entre pastas y formas cerámicas

(C) Juan Villanueva

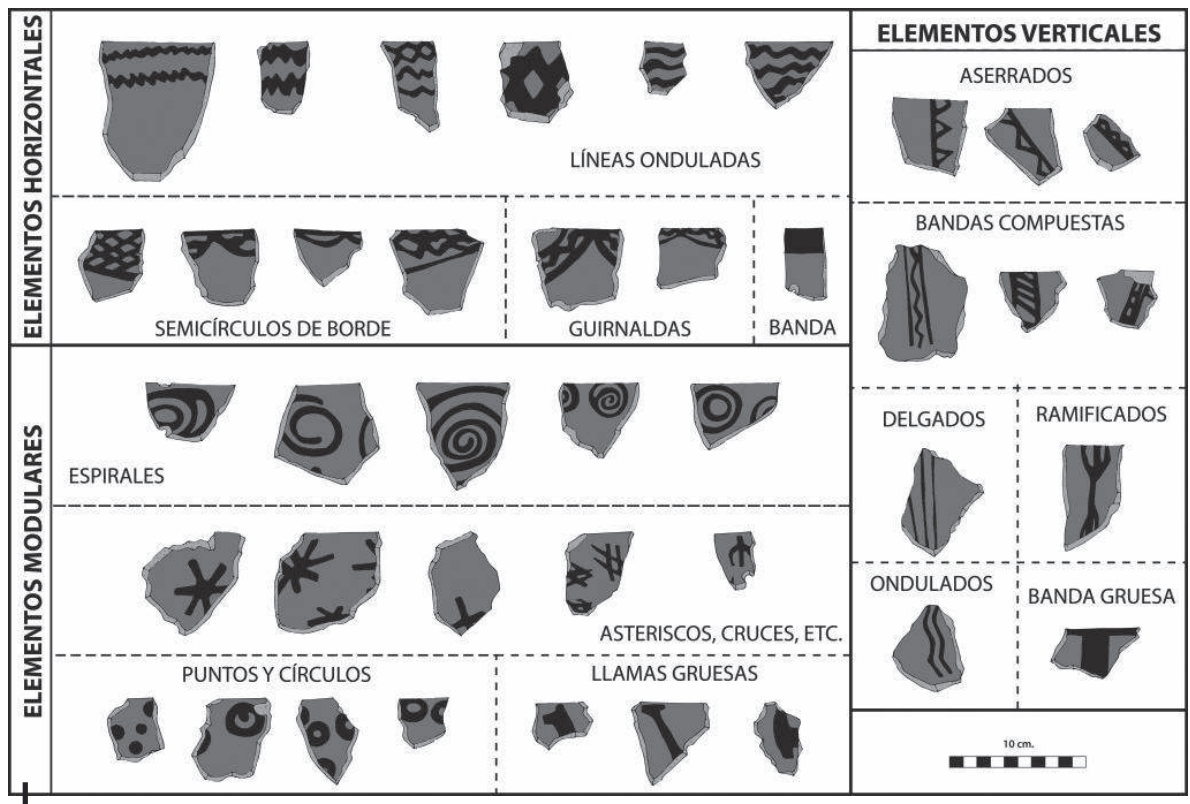

Figura 7 - Motivos decorativos en cerámica recolectada en el altiplano de Carangas

(c) Juan Villanueva 
Ponderando las frecuencias de estos motivos (fig. 8), aquellos «típicos» del estilo Carangas representan el $50 \%$ de la muestra: las líneas onduladas $30 \%$ - y las espirales $20 \%$. Las guirnaldas y bandas verticales compuestas siguen con $6 \%$. Enseguida, tenemos otros elementos verticales, como líneas delgadas y onduladas, con $4 \%$, y otros motivos modulares como cruces y puntos, con $3 \%$. Es importante observar la distribución por regiones. Si un motivo puede considerarse como mayoritario en todas las regiones estudiadas, son las líneas onduladas horizontales que forman parte del estilo Carangas (Michel, 2000), aunque se suelen afiliar más al estilo Quillacas del sur del lago Poopó (Michel, 2008). Sin embargo, es cierto que este motivo tiene más presencia en la franja sur de Carangas. El segundo motivo mayoritario, la espiral, también se ha usado como un marcador del «estilo Carangas» (Michel, 2000). Se distribuye de modo parecido, siendo más común en la franja sur, aunque es especialmente escaso en la región noreste.

Si las espirales y ondulados horizontales son más comunes en el sur de Carangas, las bandas verticales compuestas son mucho más usuales al norte, especialmente en la región noreste, donde constituyen el segundo motivo mayoritario. Las guirnaldas, el cuarto motivo más frecuente, aparecen en la franja oriental, mayormente en el sudeste. Otro motivo vinculado a la mitad oriental son las bandas oscuras gruesas. El noroeste de Carangas se distingue de las otras regiones por emplear variados motivos verticales (aserrados, ondulados y líneas delgadas) y modulares como puntos, círculos, asteriscos y llamas gruesas, que no aparecen en otras regiones. En comparación, la región sudoeste es la más apegada al «típico» estilo Carangas, incluyendo poca variedad aparte de las espirales y ondulados horizontales.

\section{4. Relacionando pastas y motivos pintados}

La distribución de las pastas en relación con los motivos pintados fue estudiada empleando aquellos cuencos decorados que habían sido sujetos a análisis petrográfico de pastas (407 tiestos), lo que dio la gráfica siguiente (fig. 9).

La principal conclusión es que no hay un vínculo exclusivo entre alguna pasta y algún motivo. La mayoría de las pastas fueron empleadas para hacer cuencos decorados con variedad de motivos. Las excepciones son las minoritarias pastas 5 y 4. La pasta 5 se relaciona con el motivo espiral como todas las demás, pero también con la banda horizontal simple, propia del oriente de Carangas. La pasta 4 aparece solamente con el motivo vertical aserrado, propio del noroeste. Esto implica que, en cuencos hechos con pastas casi exclusivas de la región sudoeste, se plasmaron motivos que son más comunes en regiones vecinas.

Las tres pastas mayoritarias (pasta 1, pasta 2-3 y pasta 6) se usaron para realizar piezas con motivos variados. La pasta 6, que se concentra en la región noreste, no se relaciona especialmente con ningún motivo. Se encuentra ausente de cuencos con semicírculos, guirnaldas, bandas simples y motivos verticales delgados, que interesantemente se asocian a la franja oriental de Carangas. En cambio, la pasta 1 exhibe correlaciones más fuertes con los puntos modulares, aserrados y verticales 


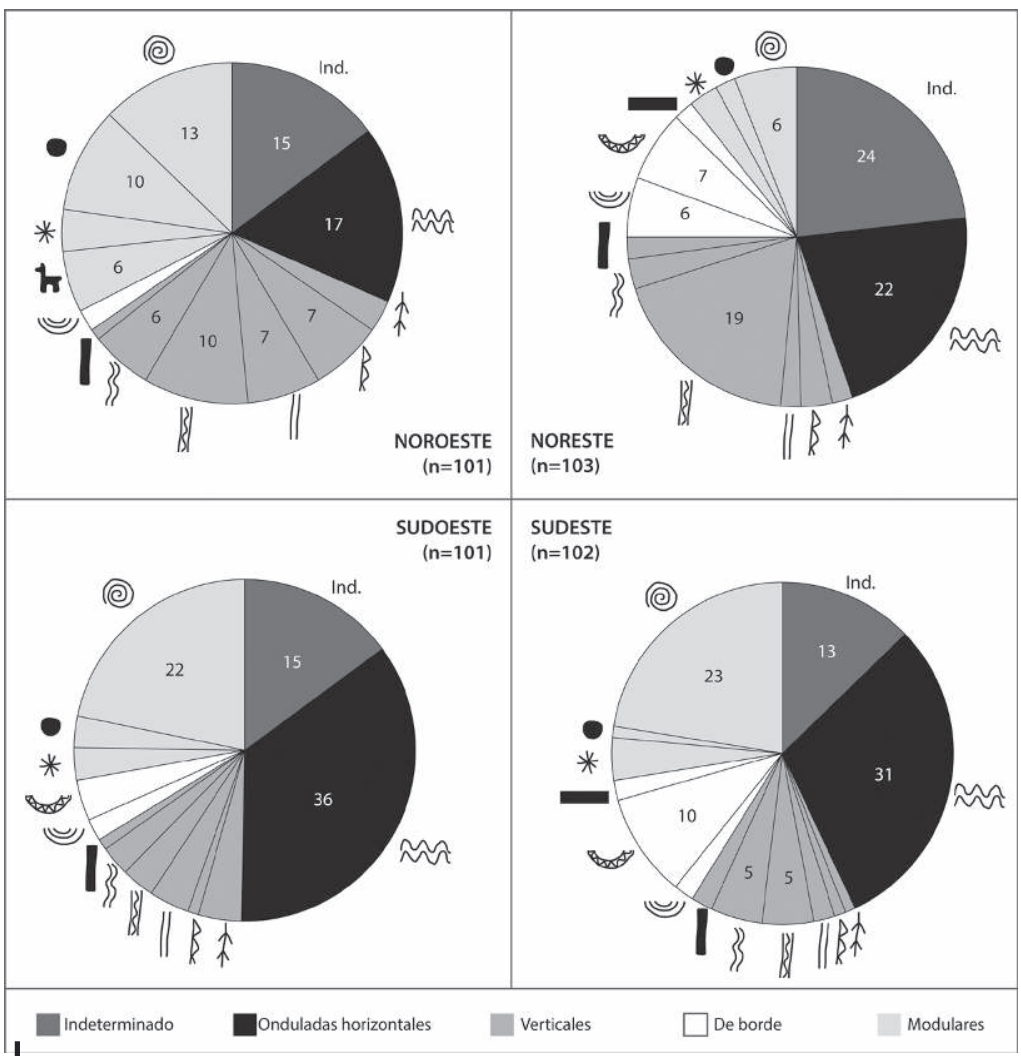

Figura 8 - Gráfico de distribución de motivos decorativos según la región

(c) Juan Villanueva

ramificados, propios de la franja occidental. La pasta 1 es también exclusiva del motivo de guirnalda, asociado al sudeste y a la franja oriental. Esta relación es llamativa, dado que la pasta 1 es mayoritaria en el noroeste de Carangas; por lo mismo, es notable que no aparezcan en el análisis cuencos de pasta 1 con asteriscos, que son motivos propios del noroeste.

La pasta 2-3 se distribuye entre ocho motivos, repartidos por todas las regiones (ondulados horizontales y espirales), que tienden a ser plasmados en cuencos de esta pasta, aunque la relación no es exclusiva. La pasta 2-3 se asocia también a los semicírculos de borde, motivo minoritario pero distribuido homogéneamente, y a motivos típicos del noroeste como verticales ondulados, bandas compuestas y verticales delgados; una vez más, esto llama la atención porque el noroeste tiene menor preferencia por la pasta 2-3. Esta pasta también es mayoritaria en los cuencos con asteriscos, comunes en el noroeste. 


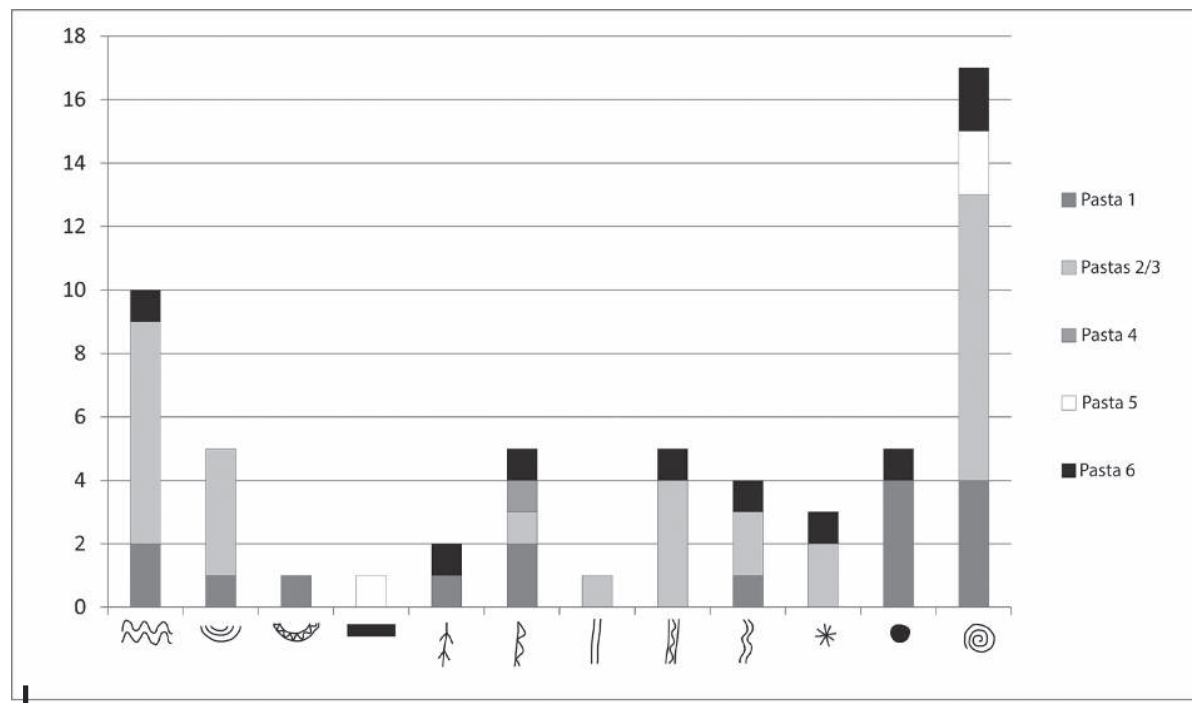

Figura 9 - Gráfico de la relación entre los motivos decorativos y las pastas cerámicas

(C) Juan Villanueva

\section{DISCUSIÓN EN RELACIÓN CON EL MODELO ETNOGRÁFICO DE ALFAREROS GOLONDRINOS}

Una problemática que motivó este trabajo fue el tratamiento dado tradicionalmente a la cerámica del Intermedio tardío, con base en el concepto de estilo externo y su postulada correspondencia con identidades étnicas. Este enfoque no solamente procede de contextos y agendas políticas superadas, sino adolece de problemas metodológicos, como el énfasis cladístico y la ahistoricidad. Además, no resiste estudios comparativos entre los supuestos territorios de señoríos que deberían ser representados por cada estilo. Considerar los modos de construcción de comunidades imaginadas sobre la base de la confluencia ceremonial-; implica repensar el rol de la cerámica, desplazándola de un signo de diferencias y fronteras a un agente que facilita la interacción entre segmentos.

Nuestro principal argumento para desarmar el andamiaje del señorío preincaico de Carangas partió del examen detallado de cuatro regiones de su supuesto territorio, mostrando la heterogeneidad interna a esta zona altiplánica. Más allá de la diversidad climática, ecológica y de patrones de asentamiento, que no hemos abordado en esta ocasión, resalta la diversidad de pastas y motivos cerámicos. Así, se debilita la idea de un «estilo Carangas» homogéneo y compartido por los habitantes de todo este territorio como emblema étnico, que es una de las bases en que se sustenta la definición de este señorío para tiempos preincaicos (Michel, 2000: 85).

Ahora bien, si planteamos que en las instancias ceremoniales confluyen segmentos sociales de diferentes lugares, quizá diferentes regiones de Carangas, ¿no sería una posibilidad que cada segmento aporte su propio utillaje cerámico a la ceremonia? 
Hemos observado una diversidad de pastas, algunas potencialmente indicadoras de diferentes fuentes de materiales y, por tanto, de diferentes regiones del altiplano, que fluyen sobre este espacio. Estos utillajes, entonces, ¿estarían representando identidades étnicas internas a Carangas en las instancias ceremoniales? Preferimos evitar esta interpretación, que reproduce el pensamiento cladístico a escala más pequeña, por dos razones. Primero, no existe una correspondencia estricta entre los motivos pintados y las pastas cerámicas. En el supuesto de que los motivos representasen la identidad étnico-territorial de un segmento social, y este segmento incluyese a alfareros que comparten esta identidad, se esperaría una coincidencia entre el motivo decorativo y la pasta, un escenario que contradicen nuestros datos. Asimismo, las características de diseño o decoración de un ceramio no responden únicamente a la necesidad de representar identidad étnica. El diseño puede entenderse como parte integral de un objeto, que funciona como herramienta para afectar o co-crear el mundo en relación con diferentes entidades humanas y no humanas que lo componen (Escobar, 2012: 18), más aún en contextos tan significativos ritual e ideológicamente como los ceremoniales chullparios.

La segunda razón parte de la etnografía sobre alfarería centro-sur andina, donde los alfareros constituyen o componen comunidades (Arnold et al., 1975; Cremonte, 1984; Druc, 2013; Sillar, 2000), lo que implica preguntarnos la manera en que se insertan en las redes de intercambio y en la construcción de comunidades. La discrepancia entre pasta y motivo decorativo detectada llama la atención sobre las diferentes agencias que operan sobre los pasos de la cadena productiva cerámica. Desde los Andes peruanos, Druc (2013: 492) sugiere que los materiales que constituyen la pasta cerámica pueden emplearse para definir qué es una cerámica «local», aunque Ilama la atención sobre los efectos que tendría el fenómeno de alfarería itinerante en la definición exacta de la cerámica «local» cuando se la detecta en contextos de uso (Druc, 2013: 503). El hecho de que se pinte la cerámica con motivos preferidos por cada región en cuencos realizados con pastas provenientes de otras diversas regiones, resuena con el modelo de un alfarero que transporta sus materiales para ejecutar formas y decorados «a pedido» del consumidor, al interior del fenómeno de alfareros itinerantes o alfareros golondrinos, en términos de Ramón (2013).

Dicha alfarería golondrina presenta una compleja variabilidad de modalidades. Como sugiere Ramón (2013), no basta con detectar diversidad de pastas para postular la existencia de alfareros golondrinos. Sin embargo, la fusión de estilos, cuando se mantiene estable el estilo técnico de los alfareros, sí podría interpretarse como un rasgo de esta práctica de producción e intercambio de alfarería (Ramón, 2013: 108). Nuestro análisis sobre la cerámica del Intermedio tardío en Carangas podría reflejar este fenómeno: rasgos del ceramio como los motivos pintados, que tienden a incorporarse al «estilo externo», responderían a las preferencias de los usuarios de la cerámica. Mientras tanto, otros rasgos de estilo técnico están en control del alfarero, concretamente las pastas cerámicas, que emplean distintas fuentes de materiales o antiplásticos. Para comprobar esta hipótesis, deberán hacerse más análisis sobre otras decisiones técnicas, como los procesos de formación de la pieza, el tratamiento superficial o la cocción. 
La práctica de alfarería itinerante se suele encontrar, en la Etnografía, como un medio para intercambiar ceramios grandes que, de otro modo, podrían romperse en el transporte; tal es el caso del trabajo de Sillar (2000). Sin embargo, Ramón (2013) encuentra que esta práctica no necesariamente se restringe a piezas de gran tamaño, dependiendo de las condiciones del trayecto. Aunque nuestro análisis, cruzando motivos decorativos y pasta, se centra en piezas pequeñas como los cuencos, no detectamos una especialización de pastas en la producción de piezas de ningún tamaño. Este dato podría apoyar el escenario de alfareros golondrinos, que tendrían que preparar y transportar materias primas lo suficientemente versátiles como para trabajar piezas de diferentes formas y tamaños. En todo caso, esta idea requiere ser mejor trabajada en relación con la información etnográfica.

Siguiendo a Gosselain (2016: 224-225), es importante ligar evidencias etnográficas y arqueológicas mediante un enfoque histórico directo, apuntando a realizar una historia de las técnicas, como un antídoto al énfasis exotista de una práctica etnoarqueológica transcultural. En ese sentido, se han documentado alfareros itinerantes en Pumpuri, cerca del altiplano boliviano central (Sillar, 2000). Sin embargo, tanto Pumpuri como otros casos de alfarería itinerante o distribución itinerante de alfarería descritos en Bolivia, Perú y Argentina (Cremonte, 1984; Druc, 2013; Harris, 1986; Ramón, 2013; Sillar, 2000), indican que estos alfareros son productores de regiones altas que se trasladan a pisos ecológicos más bajos a intercambiar cerámica por maíz u otros productos.

Autoras como Cremonte (1984: 256-257) se preguntan si esta conducta no sería una consecuencia de la desestructuración de las grandes formaciones sociales prehispánicas; de hecho, Harris (1986: 264-265) apunta que, en zonas como el norte de Potosí, donde el esquema social precolonial de ayllus y markas no fue fuertemente afectado, los alfareros intercambian su producto con otros ayllus menores, al interior del ayllu mayor. En el caso del Carangas preincaico, plantearíamos un escenario donde los materiales cerámicos se desplazan al interior del altiplano de carangas, sin atravesar pisos ecológicos. Sin embargo, como describimos, la franja oriental de Carangas tiene suelos, orografía y clima que le otorgan una vocación agrícola, mientras que la franja occidental tiene un carácter más fuertemente pastoril. Este factor no carece de importancia. Arnold et al. (1975: 190-191) sugieren que la alfarería es una adaptación a tierras con pobre agricultura, y Sillar (2000: 91-92) la relaciona con la propiedad sobre rebaños de llamas, sobre todo para la práctica itinerante.

En todo caso, en nuestra prospección en Carangas detectamos poblaciones importantes asentadas en entornos hostiles a la práctica agrícola, como la región sudoeste, que precisamente alberga la mayor variedad de pastas cerámicas. Es imposible demostrar, en el estado actual de la investigación, que la cerámica de Carangas haya sido manufacturada por habitantes del sudoeste, pero al menos dos pastas diferenciadas por peculiaridades en sus inclusiones —una muy micácea y la otra feldespática — se distribuyen casi exclusivamente en dicha región. Otro rasgo que resuena con algunas descripciones de alfareros itinerantes es la cercanía del sudoeste a fuentes de sal, otro recurso para el intercambio caravanero. 
Una consecuencia de este análisis es que la distribución mayor de cerámica y su uso en dinámicas comensalistas de construcción de comunidades imaginadas fue más intensa en el sudoeste más árido y pastoril, mientras que la capital etnohistórica del señorío Carangas se ubica en las zonas más ricas en recursos agrícolas del noreste, donde, en tiempos inka, se habría instalado un centro de redistribución de recursos y bienes (Michel, 2000: 66). Una hipótesis es que el señorío Carangas sea un fenómeno histórico incaico o posterior, y que no sea lo más apropiado extrapolar su existencia al Intermedio tardío. En este último, más que una entidad étnico-territorial jerarquizada y estable, tendríamos un escenario sociopolítico más descentralizado y fluido, donde poblaciones pastoriles, móviles y alfareros itinerantes ocuparían un rol destacado en constantes dinámicas de negociación del poder y construcción de comunidades mediante el ceremonial comensalista.

Más allá de nuestro caso de estudio, pensamos que considerar la cerámica como una herramienta de confluencia más que como un símbolo de fronteras sociales y divisiones, puede ser productivo para repensar el Intermedio tardío altiplánico y parte de la arqueología centro-sur andina. En ese sentido, la interacción entre arqueología y etnografía de las prácticas alfareras no persigue solamente el «hallazgo» de alfareros itinerantes precoloniales, sino que nos impele a cuestionar y relativizar supuestos arraigados en nuestros modelos arqueológicos tradicionales, fundamentalmente el rol del estilo como reflejo de identidad. Aunque coincidimos con la crítica de Gosselain (2016: 223) al carácter exotista de la etnoarqueología, pensamos que se puede realizar una historia de las técnicas desde un enfoque histórico directo, contextualizado. Desde este punto de vista, emplear a los olleros para repensar críticamente los andamiajes arqueológicos tradicionales, e incluir el estudio de los estilos técnicos en nuestros procedimientos analíticos, es fundamental para plantear alternativas de interpretación.

\section{Agradecimientos}

Este trabajo se basa en mi proyecto de tesis doctoral al interior del Programa de Posgrado en Antropología de la Universidad Católica del Norte-Universidad de Tarapacá en Arica, Chile. Ese proyecto no hubiera sido posible sin el apoyo de Marcela Sepúlveda como Profesora Guía. Agradezco asimismo a las autoridades nacionales, departamentales, municipales y comunales que acogieron este proyecto, a todos los amigos que formaron parte del PAAC en sus temporadas de campo y análisis, a Guillermo De la Fuente por la enseñanza de las bases del análisis petrográfico, y a José Cárcamo y Sebastián Gutiérrez, de LAIA, por su apoyo durante el análisis de materiales. Finalmente, a Catherine Lara y Gabriel Ramón por la gentil invitación a formar parte de este volumen y por los útiles comentarios editoriales, así como a los revisores anónimos cuyos apuntes enriquecieron mucho este texto. 
Altiplano de Carangas: estilo técnico cerámico del Intermedio tardío (ap. 1100-1450 d. C.)

\section{Referencias citadas}

ALBARRACÍN-JORDÁN, J., 1996 - Tiwanaku: Arqueología regional y dinámica segmentaria, xiv + 393 pp.; La Paz: Plural.

ALBARRACÍN-JORDÁN, J., 2007 - La formación del Estado prehispánico en los Andes: origen y desarrollo de la sociedad segmentaria indígena, xxiv +236 pp.; La Paz: Fundación Bartolomé de Las Casas.

ANDERSON, B., 1983 - Imagined communities. Reflections on the Origin and Spread of Nationalism, 240 pp.; Londres \& Nueva York: Verso.

ARELLANO, J. \& BERBERIÁN, E., 1981 - Mallku: El señorío Post-Tiwanaku del Altiplano sur de Bolivia (Provincias Nor y Sur Lípez-Dpto. de Potosí). Bulletin de I'Institut Français d'Études Andines, 10 (1-2): 51-84.

ARNOLD, D. E., BROCKINGTON, D. L., CHATTERJEE, B. K., HOWRY, J. C., ISBELL, W. H., KRESZ, M., MYERS, T. P., ONUKI, Y., PEARSON, R., PRASAD, S., RAVINES, R., RAYMOND, J. S., SHARMA, J. C. , Webster, S. \& Orr Whyte, R., 1975 Ceramic Ecology of the Ayacucho Basin, Peru: Implications for Prehistory. Current Anthropology, 16 (2): 183-205.

ARNOLD, D. E., 2003 - Ecology and ceramic production in an Andean Community, xxxi + 278 pp.; Cambridge: Cambridge University Press. New Studies in Archaeology.

ARELLANO LÓPEZ, J. \& KULJIS, D., 1986 - Antecedentes preliminares de las investigaciones arqueológicas en la zona circumtiticaca de Bolivia. Prehistóricas, 1: 9-28.

BENNETT, W. C., 1934 - Excavations at Tiahuanaco, 494 pp.; Nueva York: Anthropological Papers of the American Museum of Natural History, Vol. XXXIV, Part III.

BERNARDINI, W., 2005 - Reconsidering Spatial and Temporal Aspects of Prehistoric Cultural Identity: A Case Study from the American Southwest. American Antiquity, 70 (1): 31-54.

BOUYSSE-CASSAGNE, T., 1987 - La identidad Aymara. Aproximación histórica (siglo XV, siglo XVI), 443 pp.; La Paz: Hisbol, IFEA.

CREMONTE, M. B., 1984 - Alfareros itinerantes de Los Colorados (Dto. Tafí, Tucumán). Aproximaciones a un estudio de etnografía arqueológica. Runa, vol. 14: 247-263.

DIETLER, M., 1996 - Feasts and Commensal Politics In the Political Economy: Food, Power and Status In Prehistoric Europe. In: Food and the Status Quest: An Interdisciplinary Perspective (P. Wiessner \& W. Shieffenhövel, eds.): 87-125; Providence: Berghahn Books.

DRUC, I., 2013 - What is local? Looking at Ceramic production in the Peruvian Highlands and Beyond. Journal of Archaeological Research, 69 (4): 485-513.

ESCOBAR, A., 2012 - Notes on the Ontology of Design, 85 pp.; Chapel Hill: University of North Carolina.

GIL GARCíA, F., 2010 - Dentro y fuera parando en el umbral: construyendo la monumentalidad chullparia. Elementos de tensión espacial para una arqueología del culto a los antepasados en el altiplano andino. Diálogo Andino, 35: 25-46.

GOSSELAIN, O., 2016 - To hell with ethnoarchaeology! Archaeological Dialogues, 23 (2): 215-228.

HARRIS, O., 1986 - From asymmetry to triangle, symbolic transformations in Northern Potosí. In: Anthropological History of Andean Polities (J. Murra, N. Wachtel \& J. Revel, eds.): 260-280; Cambridge University Press. 
ISBELL, W., 2000 - What we should be studying: the "imagined community" and the "natural community". In: The Archaeology of Communities. A New World Perspective (M. A. Canuto \& J. Yaeger, eds.): 242-266; Londres y Nueva York: Routledge.

KESSELI, R. \& PÄRSSINEN, M., 2005 - Identidad étnica y muerte: torres funerarias (chullpas) como símbolos de poder étnico en el altiplano boliviano de Pakasa (1250-1600 d.C.). Bulletin de I'Institut Français d'Études Andines, 34 (3): 379-410.

LECOQ, P., 1999 - Uyuni Préhispanique : Archéologie de la Cordillère Intersalar (Sud-Ouest Bolivien), 327 pp.; Oxford: BAR International Series.

LECOQ, P., 1985 - Ethnoachéologie du salar d'Uyuni "Sel et cultures régionales Inter Salar". Bulletin de I'Institut Français d'études Andines, XIV (1-2): 57-84.

MEDINACELLI, X., 2008 - Los Pastores de Carangas y la territorialidad dispersa en el siglo XVI. In: La Iglesia de Curahuara de Carangas. La Capilla Sixtina del Altiplano (H. Van den Berg, ed.): 17-24; La Paz: UCB, MUSEF, Plural editores.

MEDINACELLI, X., 2010 - Sariri: Ios Ilameros y la construcción de la sociedad colonial, 390 pp.; La Paz: IFEA, ASDI, Plural, IEB-UMSA.

MICHEL, M., 2000 - El señorío prehispánico de los Caranga, 95 pp.; La Paz: Universidad de la Cordillera.Tesis inédita de Diplomado Superior en Derecho de los Pueblos Indígenas.

MICHEL, M., 2008 - Patrones de Asentamiento Precolombino en el Altiplano Boliviano: Lugares centrales de la región de Quillacas, Departamento de Oruro, Bolivia, 214 pp.; Tesis doctoral inédita; Uppsala: Uppsala Universitet.

MOBAREC, R. \& MURILlO, F., 1996 - Geología. In: Hojas Corque y Nevados Payachata. Mapas Temáticos de Recursos Minerales de Bolivia (H. Tröeng \& F. Riera, eds.): $27-$ 74; La Paz: GEOBOL.

MONTES DE OCA, I., 2005 - Enciclopedia Geográfica de Bolivia, 871 pp.; La Paz, Editora Atenea.

MUÑOZ OVALLE, I. R. \& CHACAMA RODRÍGUEZ, J., 2006 - Complejidad Social en las alturas de Arica: Territorio, etnicidad y vinculación con el estado Inca, 392 pp.; Arica: Ediciones Universidad de Tarapacá.

NIELSEN, A., 2006 - Pobres Jefes: Aspectos Corporativos en las Formaciones Sociales Pre-Incaicas de los Andes Circumpuneños. In: Contra la Tiranía Tipológica en Arqueología: Una visión desde Suramérica (C. Gnecco \& K. Langebaek, eds.): 121 150; Bogotá: Universidad de los Andes.

NIELSEN, A., 2008 - The Materiality of Ancestors. Chullpas and social memory in the Late Prehispanic History of the South Andes. In: Memory Work: Archaeologies of Material Practices (B. H. Mills, W. H. Walker, eds.): 207-232; Santa Fe: School of American Research Press.

PÄRSSINEN, M., 2005 - Caquiaviri y la provincia Pacasa, 318 pp.; La Paz: CIMA, UMSAMaestría en Historias Andinas y Amazónicas.

PÄRSSINEN, M., KESSELI, R. \& FALDÍN, J., 2010 - Paria, the southern Inca capital rediscovered. Chungará, 42 (1): 235-246.

PATIÑO, T. \& VILLANUEVA, J., 2008 - En la ciudad de los muertos. Excavaciones arqueológicas en Wayllani-Kunturamaya. Chachapuma. Revista de Arqueología Boliviana, 3: 23-35.

PONCE SANGINÉS, C. 1976 - Tiwanaku: Espacio, Tiempo y Cultura. Ensayo de síntesis arqueológica, 251 pp.; La Paz: Ediciones Pumapunku.

PONCE SANGINÉS, C., 1978 - Panorama de la Arqueología Boliviana, 30 pp.; La Paz: Publicaciones del INAR, 27. 
Altiplano de Carangas: estilo técnico cerámico del Intermedio tardío (ap. 1100-1450 d. C.)

PORTUGAL LOAYZA, J., 2011 - Umasuyu: una entidad sociopolítica diferenciada o una parcialidad de Pakajaqi. Textos Antropológicos, 16 (1): 63-80.

RAMÓN JOFFRÉ, G., 2013 - Los alfareros golondrinos: productores itinerantes en los Andes, 167 pp.; Lima: Instituto Francés de Estudios Andinos, Sequilao editores.

PORTUGAL ORTíZ, M., 1988 - Informe de la prospección a Pacajes (Etapa 1). Arqueología Boliviana, 3: 109-117.

RIVIÈRE, G., 1988 - Dualismo y cuartipartición en Carangas. Revista del Museo Nacional de Etnografía y Folklore, 1-2: 67-121.

RODDICK, A., 2015 - Geologies in Motion. Itineraries of Stone, Clay, and Pots in the Lake Titicaca Basin. In: Things in Motion. Object Itineraries in Anthropological Practice (R. A. Joyce \& S. D. Gillespie, eds.): 123-145; Santa Fe: School of Advanced Research Press.

ROUX, V., 2011 - Anthropological interpretation of ceramic assemblages: foundations and implementations of technological analysis. In: Archaeological Ceramics: A Review of Current Research (S. Scarcella, ed.): 80-88; Oxford: Archeopress. British Archaeological Reports International Series 2193.

RYDÉN, S., 1947 - Archaeological Researches in the Highlands of Bolivia, 559 pp.; Götteborg: Eanders Boktryckeri Aktiebolag.

SAPIENCIA DE ZAPATA, S., MACEDA RASSIT, V. \& VIAÑA UZIEDA, J., 1997 - Inventario de la Cerámica Aymara y Quechua, 83 pp.; La Paz: Unión de Ceramistas Aymaras Quechuas de Bolivia, Centro de Investigación de Energía y Población.

SAIGNES, T., 1986 - En busca del poblamiento étnico de los Andes bolivianos (siglos XV y XVI), 46 pp.; La Paz: Museo Nacional de Etnografía y Folklore.

SILLAR, B., 2000 - Shaping Culture: Making Pots and Constructing Households: An Ethnoarchaeological Study of Pottery Production, Trade and Use in the Andes, viii + 219 pp.; Oxford: BAR International Series, Vol. S883, British Archaeological Reports.

STARK, M. T., 1998 - Technical Choices and Social Boundaries in Material Culture Patterning: An Introduction. In: The Archaeology of Social Boundaries (M. Stark, ed.): 1-11; Washington y Londres: Smithsonian Institution Press.

STARK, M. L.T., BISHOP, R. L. \& MIKSA, E., 2000 - Ceramic Technology and Social Boundaries: Cultural Practices in Kalinga Clay Selection and Use. Journal of Archaeological Method and Theory, 7 (4): 295-331.

VILLANUEVA CRIALES, J., 2015 - Evaluando la frontera Pacajes-Carangas para el Período Intermedio tardío (1.100-1.450 D.C.) en el altiplano boliviano central a partir del análisis de pastas cerámicas. Chungara, 47 (2): 211-218.

VILLANUEVA CRIALES, J., 2017 - Lo boliviano y lo indígena en la construcción arqueológica del post-Tiwanaku altiplánico. Narrativas no inocentes y alternativas futuras. Surandino Monográfico, 2: 1-20. 